\title{
Autoantibodies to angiotensin and endothelin receptors in systemic sclerosis induce cellular and systemic events associated with disease pathogenesis
}

Angela Kill ${ }^{1,2}$, Christoph Tabeling ${ }^{3}$, Reinmar Undeutsch ${ }^{1,2}$, Anja A Kühl ${ }^{4}$, Jeannine Günther ${ }^{1,2}$, Mislav Radic ${ }^{2,5}$, Mike O Becker ${ }^{2}$, Harald Heidecke ${ }^{6}$, Margitta Worm7, Martin Witzenrath ${ }^{3}$, Gerd-Rüdiger Burmester ${ }^{2}$,

Duska Dragun ${ }^{8}$ and Gabriela Riemekasten ${ }^{1,2^{*}}$

\begin{abstract}
Introduction: Vasculopathy, inflammatory fibrosis and functional autoantibodies (Abs) are major manifestations of systemic sclerosis (SSC). Abs directed against the angiotensin II type 1 receptor $\left(\mathrm{AT}_{1} \mathrm{R}\right)$ and endothelin-1 type $\mathrm{A}$ receptor $\left(E T_{A} R\right)$ are associated with characteristic disease features including vascular, inflammatory, and fibrotic complications indicating their role in SSC pathogenesis. Therefore, the impact of anti-AT ${ }_{1} R$ and anti-ET $A$ R Abs on initiation of inflammation and fibrosis was analyzed.
\end{abstract}

Methods: Anti-AT 1 R and anti-ET ${ }_{A} R$ Ab-positive immunoglobulin G (IgG) from SSc patients (SSc-lgG) was used for experiments. Healthy donor lgG served as a normal control, and $A T_{1} R$ and $E_{A} R$ activation was inhibited by antagonists. Protein expression was measured with ELISA, mRNA expression with real time-PCR, endothelial repair with a scratch assay, and collagen expression with immunocytochemistry. Transendothelial neutrophil migration was measured with a culture insert system, and neutrophil ROS activation with immunofluorescence. Neutrophils in bronchoalveolar lavage fluids (BALFs) were analyzed microscopically after passive transfer of SSC-lgG or NC-IgG into naïve C57BL/6J mice. KC plasma levels were quantified by a suspension array system. Histologic analyses were performed by using light microscopy.

Results: Anti-AT $T_{1}$ and anti-ET $R$ R Ab-positive SSC-lgG induced activation of human microvascular endothelial cells (HMEC-1). Elevated protein and mRNA levels of the proinflammatory chemokine interleukin-8 (IL-8, CXCL8) and elevated mRNA levels of the vascular cell adhesion molecule-1 (VCAM-1) were induced in HMEC-1. Furthermore, activation of HMEC-1 with SSc-lgG increased neutrophil migration through an endothelial cell layer and activation of reactive oxygen species (ROS). SSc-IgG decreased HMEC-1 wound repair and induced type I collagen production in healthy donor skin fibroblasts. Effects of migration, wound repair, and collagen expression were dependent on the Ab-levels. Passive transfer of anti-AT ${ }_{1} R$ and anti-ET $T_{A} R$ Ab-positive SSC-lgG into naïve $C_{57 B L / 6 J}$ mice increased neutrophil BALF counts. In parallel, increased levels of the murine functional IL-8 homologue, chemokine KC, were found in the plasma of SSc-lgG-treated mice as well as structural alterations of the lungs.

Conclusions: We conclude that angiotensin and endothelin-receptor activation via anti-AT, $R$ and anti-ET $R$ R Abs mediate pathogenic effects, indicating their contribution to pathogenesis of SSc. Therefore, anti-AT, $R$ and anti-ET ${ }_{A} R$ Abs could provide novel targets for therapeutic intervention in the treatment of SSC.

\footnotetext{
* Correspondence: Gabriela.Riemekasten@charite.de

${ }^{1}$ German Rheumatism Research Centre (DRFZ), A Leibniz Institute, Berlin,

Germany

${ }^{2}$ Department of Rheumatology and Clinical Immunology, University Hospital

Charité, Luisenstraße 13, Berlin 10117, Germany

Full list of author information is available at the end of the article
} 


\section{Introduction}

Systemic sclerosis (SSc) is an autoimmune disorder with severe clinical manifestations, high mortality, and limited therapeutic options. Autoimmunity, vasculopathy, and fibrosis are hallmarks of the disease [1,2]. So far, mechanisms by which these hallmarks may be linked together are not well understood. Recent work from our group has shown that anti- $\mathrm{AT}_{1} \mathrm{R}$ and anti-ET $\mathrm{A}$ Abs are present in SSc [3], and that elevated Ab levels in sera are correlated with major disease manifestations, emphasizing their potential role in SSc pathogenesis. It is well established that microvascular damage, featuring endothelial cell dysfunction and perivascular infiltrates, is a key event in SSc pathogenesis appearing early in the course of the disease and preceding fibrosis [4-6]. Inflammation also is a crucial event in SSc development and is reflected by abnormal chemokine and cytokine levels in sera and BALF [7-9], as well as by inflammatory infiltrates $[2,4]$. Of note are elevated levels of IL-8, both in sera and in BALF $[7,9,10]$. Furthermore, the latter were connected to neutrophilic alveolitis in SSc-related interstitial lung disease [7,11], demonstrating a link between increased IL-8 levels and neutrophil accumulation.

Progressive fibrosis is characterized by amplified production of extracellular matrix (ECM) components including increased collagen synthesis by fibroblasts. SSc skin fibroblasts have been demonstrated to produce higher amounts of collagen when compared with skin fibroblasts from healthy donors $[12,13]$. Similarly, increased collagen expression was found in an animal model of SSc [14].

Last, an increased activation of the angiotensin and endothelin axis has been reported in SSc [15-17]. Accordingly, we reasoned that anti- $\mathrm{AT}_{1} \mathrm{R}$ and anti-ET $\mathrm{A} \mathrm{R}$ Abs could directly contribute to the initiation of inflammation and fibrosis in vitro and in vivo by activation of endothelial cells, fibroblasts, and neutrophils and thus contribute to the key pathogenic manifestations of SSc. The objective of this study was to analyze the impact of functional anti- $\mathrm{AT}_{1} \mathrm{R}$ and anti-ET $\mathrm{A} \mathrm{R}$ Abs on inflammatory and fibrotic events to help understand their role in disease pathogenesis.

\section{Methods}

Reagents

All reagents were purchased from Sigma Aldrich (Germany), if not otherwise stated.

\section{Ethical admission for patient sample collection and performance of animal experiments}

Serum was collected from venous blood after written informed consent and local ethics committee approval (EA1/013/705). Healthy donor skin was obtained by biopsy after written informed consent and approval by University Hospital Charité ethics committee (EA1/168/06).
C57BL/6J mice were obtained from Charles River (Sulzfeld, Germany). Experiments were performed according to institutional and federal guidelines (Landesamt für Gesundheit und Soziales, Berlin, Germany).

\section{Patients and healthy control donors}

SSc patients with diffuse or limited SSc were classified according to LeRoy and ACR criteria [1,18]. Patients with established vasculopathy and/or fibrosis, including pulmonary arterial hypertension (PAH), lung and skin fibrosis, were chosen for IgG isolation that subsequently was used for experiments. Healthy control subjects served as negative controls. Identical IgG processing was used for SSc patients and healthy donors for serum collection and IgG isolation. For functional assays, individual IgG samples were used that were isolated from one serum sample as described later, followed by measurement of anti- $\mathrm{AT}_{1} \mathrm{R}$ and anti-ET $\mathrm{E}_{\mathrm{A}} \mathrm{R}$ Abs levels of each sample, as previously reported [3]. For animal experiments, the same methods were used, except that IgG was isolated from a pool of sera (from several patients or healthy donors) to provide enough material. Detailed patient and healthy donor control characteristics are summarized in Table 1.

\section{Isolation of IgG and detection of anti-AT $R$ and anti-ET ${ }_{\mathrm{A}} \mathrm{R}$ Abs}

IgG was isolated by protein-G sepharose chromatography in $20 \mathrm{~m} M$ phosphate buffer $\mathrm{pH}$ 7.0. IgG was eluted with $0.1 \mathrm{M}$ glycine $/ \mathrm{HCl}, \mathrm{pH} 2.7$, and $\mathrm{pH}$ was neutralized with 1 $M$ Tris/ $/ \mathrm{HCl}, \mathrm{pH}$ 9.0. Eluted IgG was dialyzed against PBS, and absorbance was measured at $280 \mathrm{~nm}$ (Emax, Molecular Devices, USA). Anti- $\mathrm{AT}_{1} \mathrm{R}$ and anti-ET $\mathrm{A}_{\mathrm{A}} \mathrm{R}$ Abs were detected in purified IgG in cooperation with CellTrend $\mathrm{GmbH}$ (Germany) with a commercially available solidphase assay (One Lambda, Inc., USA), as described previously [3].

\section{Cultivation and treatment of cells}

Human microvascular endothelial cells-1 (HMEC-1s) were serum-starved before all experiments in endothelial cell medium with IgG-free fetal calf serum (FCS) 0.5\%, penicillin, $100 \mathrm{U} / \mathrm{ml}$; streptomycin, $100 \mu \mathrm{g} / \mathrm{ml}$, hydrocortisone, $25 \mu M$, epidermal growth factor $0.01 \mu \mathrm{g} / \mathrm{ml}$, and L-glutamine, $10 \mathrm{mM}$. Cells were incubated in a humidified atmosphere at $5 \% \mathrm{CO}_{2}$ and $37^{\circ} \mathrm{C}$. Human fibroblasts were isolated from healthy donor skin. Dermis was removed by dispase $(4 \mathrm{mg} / \mathrm{ml})$, and epidermis was digested with collagenase type $1 \mathrm{~A}(1 \mathrm{mg} / \mathrm{ml})$. Fibroblasts were cultivated in DMEM with IgG-free FCS, 10\%, penicillin, $100 \mathrm{U} / \mathrm{ml}$, streptomycin, $100 \mu \mathrm{g} / \mathrm{ml}$, and amphotericin B, $2.5 \mu \mathrm{g} / \mathrm{ml}$. For all experiments, passages three to eight were serum-starved before experiments in DMEM with IgG-free FCS $1 \%$, penicillin $100 \mathrm{U} / \mathrm{ml}$, streptomycin 
Table 1 Patient and healthy donor characteristics

\begin{tabular}{|c|c|c|}
\hline Parameter & SSc patients $(n=33)$ & Healthy donors $(n=13)$ \\
\hline Mean age, years (SD) & $55(13)$ & $43(7)$ \\
\hline Females/males, $n$ (\%) & $24 / 9(73 / 27)$ & $9 / 4(69 / 31)$ \\
\hline Mean anti-AT ${ }_{1} R$ Abs, units (SD) & $16(8)$ & $9(4)$ \\
\hline Mean anti-ETA $R$ Abs, units (SD) & $15(10)$ & $6(4)$ \\
\hline Diffuse cutaneous form, limited cutaneous form, other, $n(\%)$ & $21(64), 10(30), 2(6)$ & n.a. \\
\hline Scl 70 positive, $n(\%)$, n.d. $n(\%)$ & $13(39), 3(90)$ & n.a. \\
\hline Anti-centromere positive, $n(\%)$, n.d. $n(\%)$ & $4(12), 4(12)$ & n.a. \\
\hline Duration since Raynaud phenomenon, years $( \pm S D$ ) & $10(11)$ & n.a. \\
\hline Duration since skin-involvement onset, years $( \pm S D)$ & $9(7)$ & n.a. \\
\hline Duration since internal organ onset, years $( \pm S D)$ & $8(7)$ & n.a. \\
\hline mRSS median (IQR) & $8(4-18)$ & n.a. \\
\hline Pulmonary arterial hypertension, $n(\%)^{\mathrm{a}}$ & $14(42)$ & n.a. \\
\hline Lung fibrosis, $n(\%)^{b}$ & $18(55)$ & n.a. \\
\hline Mean DLCO\% (SD) & $50(20)$ & n.a. \\
\hline Mean FVC\% (SD) & $85(18)$ & n.a. \\
\hline Animal experiments & SSc patients $(n=14)$ & Healthy donors $(n=15)$ \\
\hline Mean age, years (SD) & $57(14)$ & $47(8)$ \\
\hline Females/males, $n(\%)$ & $11 / 3(79 / 21)$ & $12 / 3(80 / 20)$ \\
\hline Mean anti-AT ${ }_{1} R$ Abs, units (SD) & $18(10)$ & $6(4)$ \\
\hline Mean anti-ET $T_{A} R$ Abs, units (SD) & $17(10)$ & $4(3)$ \\
\hline Diffuse cutaneous form, limited cutaneous form, other, $n(\%)$ & $10(71), 3(21), 0(0)$ & n.a. \\
\hline Scl 70 positive, $n(\%)$, n.d. $n$ (\%) & $10(71), 1(7)$ & n.a. \\
\hline Anti-centromere positive, $n(\%)$, n.d. $n(\%)$ & $2(14), 3(21)$ & n.a. \\
\hline Duration since Raynaud phenomenon, years $( \pm S D$ ) & $11(8)$ & n.a. \\
\hline Duration since skin-involvement onset, years $( \pm S D)$ & $10(7)$ & n.a. \\
\hline Duration since internal-organ onset, years $( \pm S D)$ & $10(9)$ & n.a. \\
\hline mRSS median (IQR) & $8.5(5.3-11)$ & n.a. \\
\hline Pulmonary arterial hypertension, $n(\%)^{a}$ & $8(57)$ & n.a. \\
\hline Lung fibrosis, $n(\%)^{b}$ & $8(57)$ & n.a. \\
\hline Mean DLCO\% (SD) & $42(18)$ & n.a. \\
\hline Mean FVC\% (SD) & $77(19)$ & n.a. \\
\hline
\end{tabular}

n.d., not defined; n.a., not applicable.

${ }^{a}$ By $>35 \mathrm{~mm} \mathrm{Hg}$ sPAP in echocardiography and/or $25 \mathrm{~mm} \mathrm{Hg} \mathrm{mPAP}$ in right-heart catheterization.

${ }^{\mathrm{b}}$ By HR-CT or x-ray.

$100 \mu \mathrm{g} / \mathrm{ml}$ and amphotericin B $2.5 \mu \mathrm{g} / \mathrm{ml}$. For transendothelial migration, neutrophils were freshly isolated from healthy donor blood, as described [19]. Isolated neutrophils were added to phosphate-buffered saline (PBS)/IgG-free FCS $10 \%$, and their migration capacity was assessed with transwell culture inserts, as described later. All reagents were purchased from PAA Laboratories (Germany) and Invitrogen (Europe). For all experiments that included receptor antagonism, inhibitors were added to cell cultures 18 and 3 hours before IgG treatment. The most effective antagonist concentration was determined in serial experiments.
For individual receptor antagonism, $\mathrm{AT}_{1} \mathrm{R}$ was inhibited by valsartan, and the $\mathrm{ET}_{\mathrm{A}} \mathrm{R}$ by the selective inhibitor sitaxentan. In parallel, the $\mathrm{ET}_{\mathrm{A}} \mathrm{R}$ was inhibited by the dual antagonist bosentan. All antagonists were used at $10^{-5} \mathrm{M}$ concentration, as described earlier [16,20]. Antagonists were also applied simultaneously by combination of valsartan and sitaxentan (each at $10^{-7} \mathrm{M}$ ), or valsartan and bosentan (at $10^{-5} \mathrm{M}$ and $5 \times 10^{-7} \mathrm{M}$, respectively). For inactivation of NF- $\mathrm{BB}$, tosyl-L-phenylalanine chlormethyl ketone (TPCK) was used $\left(3 \times 10^{-6} M\right) 30$ minutes before IgG treatment. All antagonists tested nontoxic, individually or simultaneously, in a cell-viability test (WST-8; 
Dojindo, Japan). Dose-dependent experiments were performed for IL-8 protein expression, as described later (range of $0.125 \mathrm{mg} / \mathrm{ml}$ to $1.5 \mathrm{mg} / \mathrm{ml} \mathrm{IgG}$ ). An IgG concentration of $1 \mathrm{mg} / \mathrm{ml}$ was used in all experiments described. Of note, a similar IgG concentration was used previously [21]. Angiotensin II (Ang II) and endothelin-1 (ET-1) were used at $10^{-6} \mathrm{M}$ and $10^{-8} \mathrm{M}$ concentrations, respectively, and incubation times were the same as for $\operatorname{IgG}[16,20]$.

\section{Scratch assay}

For analysis of endothelial repair, uniform scratches were made by $1-\mathrm{ml}$ pipette tip in confluent HMEC-1 layers, as described [22]. HMEC-1 cells were allowed to migrate into scratch areas to close wounds for 24 hours in the presence of SSc-IgG or NC-IgG. Cells were fixed in 96\% ethanol, stained with hematoxylin and eosin (Merck, Germany), and light-microscopy pictures were taken (Leica DMIL LED, LAS-EZ 2.0, Germany). Scratch areas were semiquantified with ImageJ software by measuring relative scratch areas.

\section{RNA, CDNA, and real-time PCR}

RNA was isolated from HMEC-1 48 hours after IgG treatment by NucleoSpin RNA II (Macherey-Nagel, Germany), and cDNA was generated by M-MLV reverse transcriptase (Promega, Germany), each according to manufacturer's instructions. Real-Time PCR reactions contained $5 \mu \mathrm{l}$ of cDNA, $0.25 \mathrm{~m} M$ dNTP (Bioline, Germany), $12 \mu \mathrm{g} / \mathrm{ml}$ bovine serum albumin, $1 \times$ SYBR Green-I (Molecular Probes, Germany), 1 U Immolase (Bioline), $500 \mathrm{~m} M$ TRIS pH 8.8, $6 \mathrm{mM} \mathrm{MgCl} 2,0.5 \mathrm{nmol} / \mathrm{ml}$ primer mix (TIB MOLBIOL, Germany), and were performed in MX3000P cycler (Stratagene, Europe). Primers were designed by Primer3 [23]. IL-8 forward 5'CAA-GAG-CCA-GGA-AGAAAC-CA3', reverse 5'ACT-CCT-TGG-CAA-AAC-TGCAC3'. VCAM-1 forward 5'AAG-ATG-GTC-GTG-ATC-CTTGG3', reverse 5'GGT-GCT-GCA-AGT-CAA-TGA-GA3'. Eukaryotic translation elongation factor 1- $\alpha 1$ (EEF1A1) was used as housekeeping gene, forward 5'GTT-GATATG-GTT-CCT-GGC-AAG-C3', reverse 5'GCC-AGCTCC-AGC-AGC-CTT-C3'. Samples were analyzed with MxPro-Mx3005P (Stratagene), and expression levels were normalized to the housekeeping gene.

\section{Detection of IL-8 protein}

HMEC-1 supernatants were collected 48 hours after IgG treatment. IL-8 was measured with sandwich ELISA. The coating antibody and the biotinylated detection antibody were obtained as a matched-pairs kit from ImmunoTools (Germany). Recombinant human IL-8 was obtained from Biolegend (Germany) to generate a standard curve and streptavidin conjugated HRP was obtained from Biolegend (Germany). All reagents were used according to manufacturer's instructions. Absorbance was measured at $450 \mathrm{~nm}$ by using the $E_{\max }$ microplate reader (Molecular Devices). Data were analyzed by SoftMax Pro v5 (Molecular Devices).

\section{Transendothelial neutrophil migration and measurement of neutrophil derived ROS}

Supernatants from IgG-treated HMEC-1 (SSc-IgG or NC-IgG, 48 hours) were placed in multiwell TM 24 plates followed by confluent HMEC-1 on transwell culture inserts (3 $\mu M$ pore size, all Becton Dickinson). Anti-IL-8 antibody (AB-208-NA; R\&D Systems, Germany) was added to supernatants $(10 \mu \mathrm{g} / \mathrm{ml}) 30$ minutes before migration was assessed. Neutrophils were freshly isolated from healthy donor blood, as described earlier and added to inserts $\left(2 \times 10^{6}\right.$ cells/insert). Migrated cells were counted automatically after 4 hours (CASY; Schärfe Systems, Germany). In parallel, neutrophils were isolated as described earlier and were loaded with DCFH-DA $\left(2^{\prime}, 7^{\prime}\right.$ dichlorofluorescin diacetate, $25 \mu M$ in PBS/IgG-free FCS $1 \%$ ) in a humidified atmosphere at $5 \% \mathrm{CO}_{2}$ and $37^{\circ} \mathrm{C}$. Loaded neutrophils were washed with $37^{\circ} \mathrm{C}$ warm PBS, and $1 \times 10^{5}$ neutrophils were added to $200 \mu \mathrm{l}$ of HMEC-1 supernatants treated with IgG in a 96-well round-bottom cell-culture plate. After 30 minutes at $5 \% \mathrm{CO}_{2}$ and $37^{\circ} \mathrm{C}$, cells were washed with PBS and fixed in $2 \%$ paraformaldehyde for 30 minutes at $4^{\circ} \mathrm{C}$, washed again, and taken up in $150 \mu \mathrm{l} \mathrm{PBS}$. Cells were transferred into a white 96-well plate suitable for colorimetric analysis (F96 MicroWell; Nunc, Germany), and generation of reactive oxygen species (ROS) was analyzed at an excitation wavelength of $485 \mathrm{~nm}$ and at an emission wavelength of $538 \mathrm{~nm}$ by using a fluorescence reader (Fluoroskan Ascent, Thermo Labsystems, Germany).

\section{Collagen detection}

Confluent fibroblasts isolated from healthy donor skin were grown on glass chamber slides (Iwaki, Japan) and treated with SSc-IgG or NC-IgG for 5 days for maximum collagen expression. Cells were fixed in paraformaldehyde (2\%) and triton X-100 (0.1\%). Type I collagen immunocytochemistry was performed by using a monoclonal primary antibody reactive to human collagen protein 1A (sc-59772; Santa Cruz, Santa Cruz, CA, USA) and a secondary Cy3-conjugated antibody (C2181; Sigma-Aldrich). Nucleic DNA was stained with 4',6-diamidino-2-phenylindole dihydrochloride (DAPI). Monochrome fluorescence pictures were taken (Axioplan; Carl Zeiss MicroImaging $\mathrm{GmbH}$, Germany) at identical illumination times, and fluorescence intensity signals were analyzed relative to cell number by ImageJ software (NIH).

\section{Antibody transfer into naïve mice}

Female 7 -week-old C57BL/6J mice ( $n=7 /$ group) were maintained under specific pathogen-free conditions and 
received intravenously endotoxin-free pooled NC-IgG or SSc-IgG (800 $\mu$ g, dissolved in $100 \mu \mathrm{l} \mathrm{NaCl} 0.9 \%)$ at day 0 , as previously described for anti- $\mathrm{AT}_{1} \mathrm{R}$ Abs from preeclampsia patients to study systemic events [24]. Pooled IgG fractions were tested for anti- $\mathrm{AT}_{1} \mathrm{R}$ and anti-ET $\mathrm{A}_{\mathrm{A}} \mathrm{R}$ Abs, as described earlier. NC-IgG fraction of low $\mathrm{Ab}$ levels (anti- $\mathrm{AT}_{1} \mathrm{R}$ Abs units of 3.85 and anti-ET $\mathrm{A} \mathrm{Abs}$ units of 2.5) and SSc-IgG fraction of high Ab levels (anti- $\mathrm{AT}_{1} \mathrm{R}$ Abs units of 21.8 and anti-ET $\mathrm{A}_{\mathrm{A}} \mathrm{R}$ Abs units of 17.91) were used for transfer. At day 7 , mice were killed, blood was harvested, and BALF of the right lung was collected by using $2 \times 650 \mu \mathrm{l}$ PBS. Leukocytes were counted and differentiated by means of microscopic analysis in a blinded fashion (800 cells counted/individually). KC plasma levels were quantified by Bio-Plex array according to the manufacturer's guide. For repeated IgG treatment, female 8-week-old C57BL/6J mice $(n=7 /$ group) were maintained as described earlier. Mice were treated with NC-IgG or SSc-IgG intravenously with pooled IgG at day 1 , day 17 , day 30 , and 7 days before analysis, for a total of 100 days $(200 \mu \mathrm{g}$, dissolved in 100 $\mu \mathrm{l} \mathrm{NaCl} 0.9 \%)$. Histology analysis of the lungs was performed by paraffin embedding, hematoxylin and eosin (H\&E) staining, and light microscopy (Axioplan 2; Carl Zeiss MicroImaging GmbH).

\section{Statistical analysis}

Results were analyzed with GraphPad Prism software (version 5.02) by using Mann-Whitney $U$ test (NC-IgG compared with SSc-IgG) and Wilcoxon signed-rank test (SSc-IgG compared with SSc-IgG with blockers). Correlation analyses were performed by nonparametric correlation (Spearman) and linear-regression correlation. ${ }^{* *} P<$ 0.01 and ${ }^{*} P<0.05$.

\section{Results}

Induction of IL-8 expression and release by endothelial cells

Analysis of HMEC-1 activation by anti- $\mathrm{AT}_{1} \mathrm{R}$ and anti$\mathrm{ET}_{\mathrm{A}} \mathrm{R}$ Abs-positive SSc-IgG showed a secretion of the proinflammatory and profibrotic chemokine IL-8 into culture supernatants. A dose-dependent pattern of IL-8 protein levels was found in HMEC-1 cells on stimulation with $0.125 \mathrm{mg} / \mathrm{ml}$ to $1.5 \mathrm{mg} / \mathrm{ml} \mathrm{SSc-IgG}$, with the highest response between 0.5 and $1.5 \mathrm{mg} / \mathrm{ml}$ IgG (Figure 1A), that was not present with NC-IgG. A comparison of SSc-IgG versus NC-IgG treatment revealed increased IL8 levels with SSc-IgG treatment, with high variability in individual IgG samples $(P<0.05$; Figure $1 B)$. Increased IL-8 protein levels were reduced by individual as well as simultaneous receptor antagonism (ETR-A and ATR-A/ ETR-A, each $P<0.05$; Figure 1B). We further analyzed IL8 expression on an mRNA level and found a significant increase in SSc-IgG- over NC-IgG-treated cells $(P<0.05$;
Figure 1C). Elevated IL-8 mRNA levels were reduced by receptor antagonism, as indicated (ATR-A and AT1R-A/ ETR-A; $P<0.05$ and $P<0.01$, respectively, Figure $1 C$ ). Similarly, significantly increased mRNA levels of VCAM-1 were induced by SSc-IgG treatment compared with NCIgG $(P<0.01$; Figure 1D) and reduced by receptor antagonism (ETR-A and ATR-A/ETR-A, each $P<0.05$; Figure 1D).

\section{Induction of IL-8 and Ab-level-dependent neutrophil transendothelial migration and ROS activation}

Neutrophil recruitment and migration were analyzed by transendothelial migration and ROS generation. Supernatants of SSc-IgG-treated HMEC-1 increased healthy donor neutrophil migration through an endothelial cell layer compared with supernatants of NC-IgG-treated HMEC-1 $(P<$ 0.05; Figure 2A). Neutrophil migration toward supernatants was significantly reduced by receptor inhibitors (ATR-A, ETR-A, and ATR-A/ETR-A; all $P<0.05$, Figure 2A). Addition of an IL-8-neutralizing antibody to SSc-IgG treated samples, as well as addition of NF- $\mathrm{KB}$ inactivator TPCK, significantly decreased neutrophil transendothelial migration (each $P<0.05$, Figure 2B). Finally, SSc-IgGconditioned HMEC-1 supernatants significantly increased generation of ROS in healthy donor neutrophils compared with NC-IgG conditioned supernatants or untreated controls $(P<0.05$ and $P<0.01$, respectively, Figure $2 C)$. Statistical analyses revealed a significant correlation between neutrophil migration and anti- $\mathrm{AT}_{1} \mathrm{R}$ and anti- $\mathrm{ET}_{\mathrm{A}} \mathrm{R} \mathrm{Ab}$ levels $(r=0.5849$ and $r=0.7461$, respectively, $\mathrm{P}<0.05$ and $P<0.01$, respectively, Figure 2D).

\section{Influence on endothelial-repair function}

As we observed endothelial cell activation and neutrophil recruitment, we also analyzed the influence of anti$\mathrm{AT}_{1} \mathrm{R}$ and anti-ET $\mathrm{A}$ Abs on endothelial-repair function. Artificially generated wounds in HMEC-1 layers were analyzed in a scratch assay. Reduced cell-layer repair was reflected by a larger wound area in HMEC-1 treated with SSc-IgG compared with NC-IgG $(P<0.01$, Figure 3A and $\mathrm{B})$. Individual and simultaneous receptor antagonism improved endothelial repair of SSc-IgG-treated cells with significant scratch-area reduction (ATR-A, ATR-A/ETRA; all $P<0.05$, Figure 3B). Correlation analyses showed a significant relation between impaired endothelial repair, reflected by the wound area and anti- $\mathrm{AT}_{1} \mathrm{R}$ and anti-ET $\mathrm{ET}_{\mathrm{A}} \mathrm{R}$ Ab levels $(r=0.4111$ and $r=0.4273$, respectively; $P<0.05$, Figure 3C).

\section{Induction of collagen expression in healthy donor-skin fibroblasts}

Because profibrotic events could be induced by anti$\mathrm{AT}_{1} \mathrm{R}$ and anti-ET $\mathrm{A}$ R Abs-positive SSc-IgG in HMEC-1 and neutrophil recruitment by IL-8, we additionally 


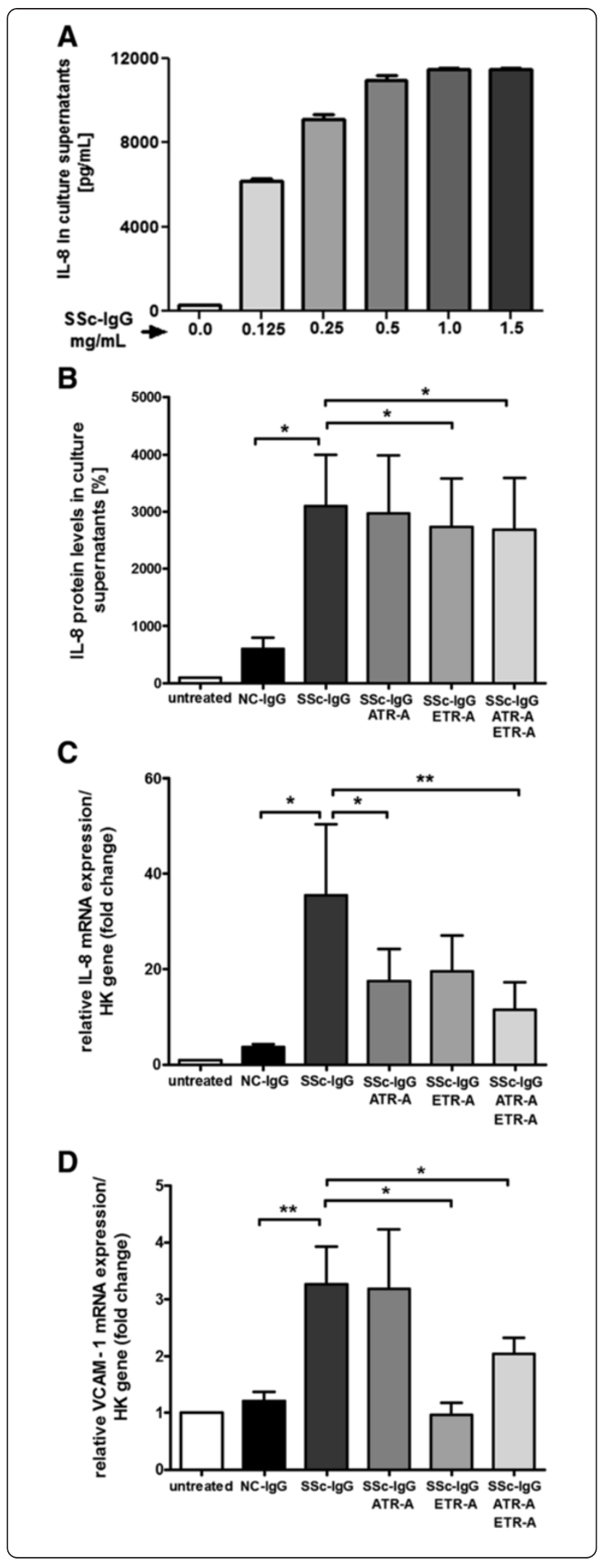

Figure 1 Activation of $\mathrm{HMEC}-1$ by anti-AT ${ }_{1} \mathrm{R}$ and anti-ET ${ }_{\mathrm{A}} \mathrm{R}$ Ab-positive SSc-IgG on protein and mRNA levels.

(A) Dose-dependent IL-8 secretion on different doses of anti-AT $T_{1} R$ and anti-ETA $R$ Ab-positive SSc-lgG. Same treatment with NC-lgG failed to demonstrate a dose-dependent IL-8 secretion pattern.

(B) Significant increase in IL-8 secretion with SSc-lgG versus NC-IgG and decrease with receptor antagonism (NC-lgG, $n=9$, SSc-lgG $n=13, P<0.05$ ). (C) Increase in IL-8 mRNA levels by SSc-lgG versus NC-lgG (NC-lgG, $n=7$, SSC-lgG $n=18, P<0.05)$. Receptor antagonism leads to inhibition of IL-8 secretion, as indicated (SSc-lgG,

$n=13, P<0.05, P<0.01)$. (D) Increase in VCAM-1 mRNA levels with SSC-lgG compared with NC-lgG (NC-lgG, $n=5$, and SSc-lgG,

$n=6 ; P<0.01)$ and inhibition by receptor antagonism as indicated $(P<0.05)$. Mean and SEM, ${ }^{* *} P<0.01$, and ${ }^{*} P<0.05$.

investigated profibrotic effects on fibroblasts as major collagen-expressing cells. Human fibroblasts were isolated from healthy donor skin, and expression of type I collagen was measured by immunocytochemistry on treatment with anti- $\mathrm{AT}_{1} \mathrm{R}$ and anti-ET $\mathrm{A}_{\mathrm{A}} \mathrm{R}$ Abs-positive SSc-IgG or NC-IgG. Increased type I collagen expression was found with SSc-IgG treatment compared with NCIgG (Figure 4A). Measurement of collagen intensity relative to cell number showed significantly increased collagen content in SSc-IgG treated cells over NC-IgG-treated cells $(P<0.05$, Figure 4B). Antagonism of ATR-A and ETR-A resulted in a marked, not significant reduction of collagen, due to high variability in the tested samples. Statistical tests demonstrated a significant correlation between collagen induction and anti-ETAR Ab levels, whereas only a marked tendency was observed to anti-AT1R Ab levels $(r=0.7619$ and $r=0.6905$, respectively; $\mathrm{P}<0.05$ and $P=0.0694$, respectively, Figure $4 \mathrm{C}$ ).

Induction of pulmonary neutrophil recruitment, increased plasma levels of murine IL-8 analogue KC, and structural alterations in lungs of naïve C57BL/6J mice

To analyze systemic effects of anti- $\mathrm{AT}_{1} \mathrm{R}$ and anti-ET $\mathrm{A} \mathrm{R}$ Abs in vivo, naïve C57BL/6J mice were subjected to passive transfer of pooled SSc-IgG or pooled NC-IgG, as previously described [24]. Seven days after the transfer, increased numbers of neutrophils were found in BALF of SSc-IgG-treated mice as compared with NC-IgGtreated mice $(P<0.01$, Figure $5 \mathrm{~A})$, whereas no differences were observed for macrophages or lymphocytes. Eosinophils were not detectable. Structural alteration of the lungs were not observed by a single IgG-treatment.

However, plasma levels of the murine IL-8 analogue $\mathrm{KC}$ were found to be increased after SSc-IgG treatment compared with NC-IgG treatment $(P=0.05$, Figure 5B). Moreover, correlation analysis of $\mathrm{KC}$ plasma levels and BALF neutrophil counts showed a strong positive correlation $\left(r^{2}=0.6756\right.$ and $\mathrm{P}=0.0019$, Figure 5C). Repeated IgG treatment resulted in profound structural alteration of the lungs, including increased cellular density and 


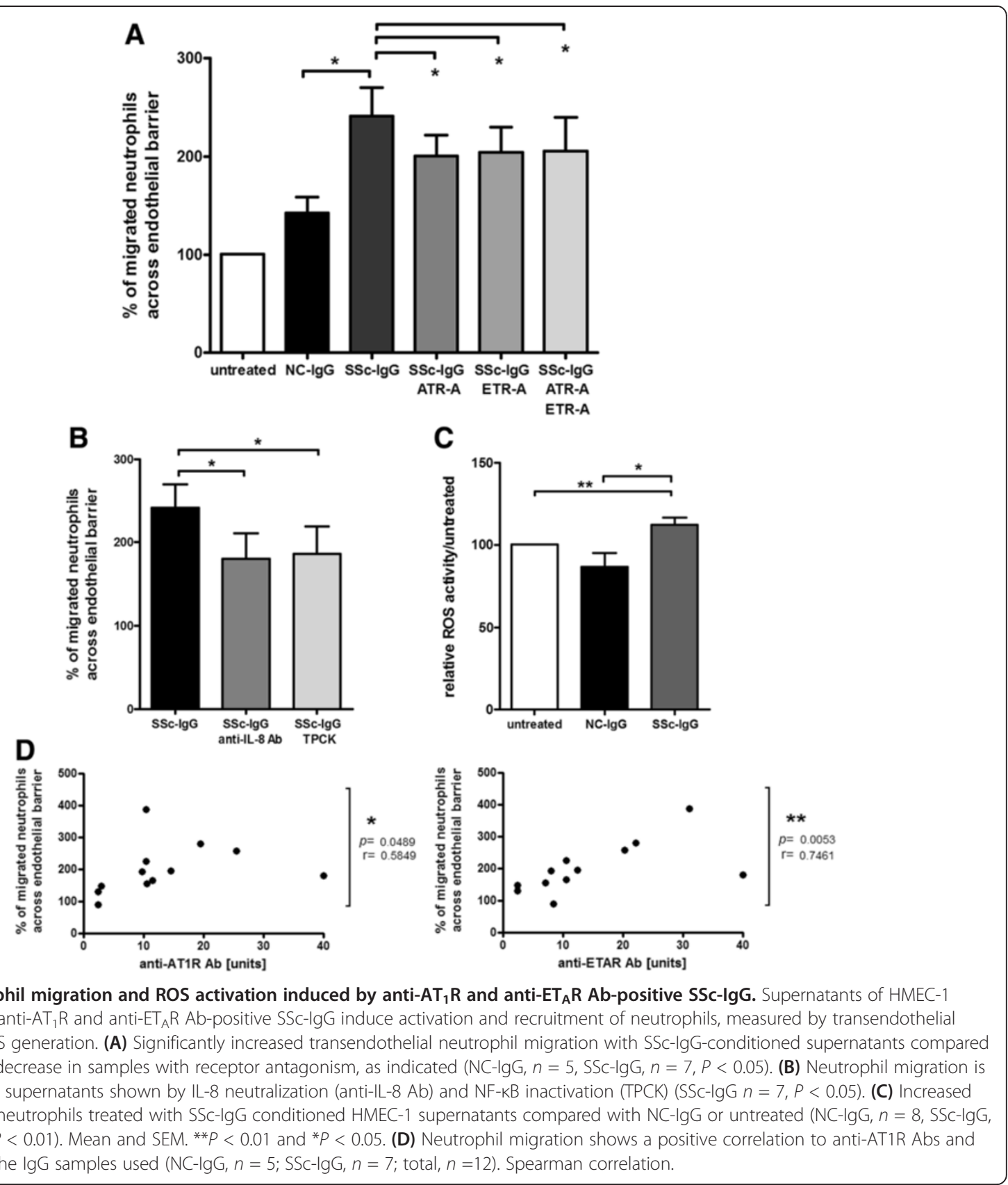

interstitial cellular infiltrations in mice treated with SSc-IgG compared with NC-IgG or untreated mice (Figure 5D).

\section{Discussion}

The purpose of this study was to analyze the impact of anti- $\mathrm{AT}_{1} \mathrm{R}$ and anti-ET $\mathrm{A}$ Abs on the induction of vascular inflammation and fibrosis, the key features of SSc. The presence of elevated anti- $\mathrm{AT}_{1} \mathrm{R}$ and anti-ET $\mathrm{E} \mathrm{Ab}$ levels in sera of SSc patients correlates with an increased risk for the development of lung fibrosis, pulmonary arterial hypertension (PAH), as well as with mortality, as demonstrated previously [3]. Furthermore, these Abs induced the expression of transforming growth factor- $\beta$ (TGF- $\beta)$ in HMEC-1s, suggesting a potential involvement in fibrosis [3]. Therefore, we sought to analyze the actions of anti- $\mathrm{AT}_{1} \mathrm{R}$ and anti-ET $\mathrm{T}_{\mathrm{A}} \mathrm{R}$ Abs with a focus on inflammation and fibrosis.

Here, we demonstrate that IgG samples from SSc patients positive for anti- $\mathrm{AT}_{1} \mathrm{R}$ and anti-ET $\mathrm{T}_{\mathrm{A}} \mathrm{R}$ Abs induce proinflammatory and fibrotic events in endothelial cells and healthy donor fibroblasts via angiotensin and endothelinreceptor activation. Besides the activation of fibroblasts, possible pathogenic effects mediated by SSc-IgG were 

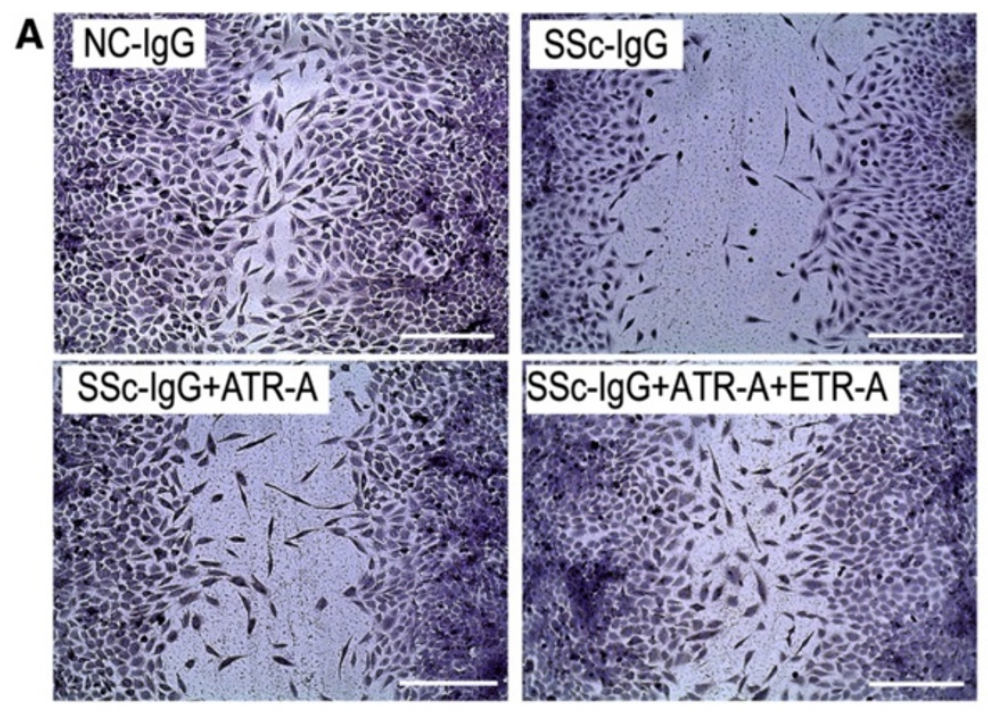

B
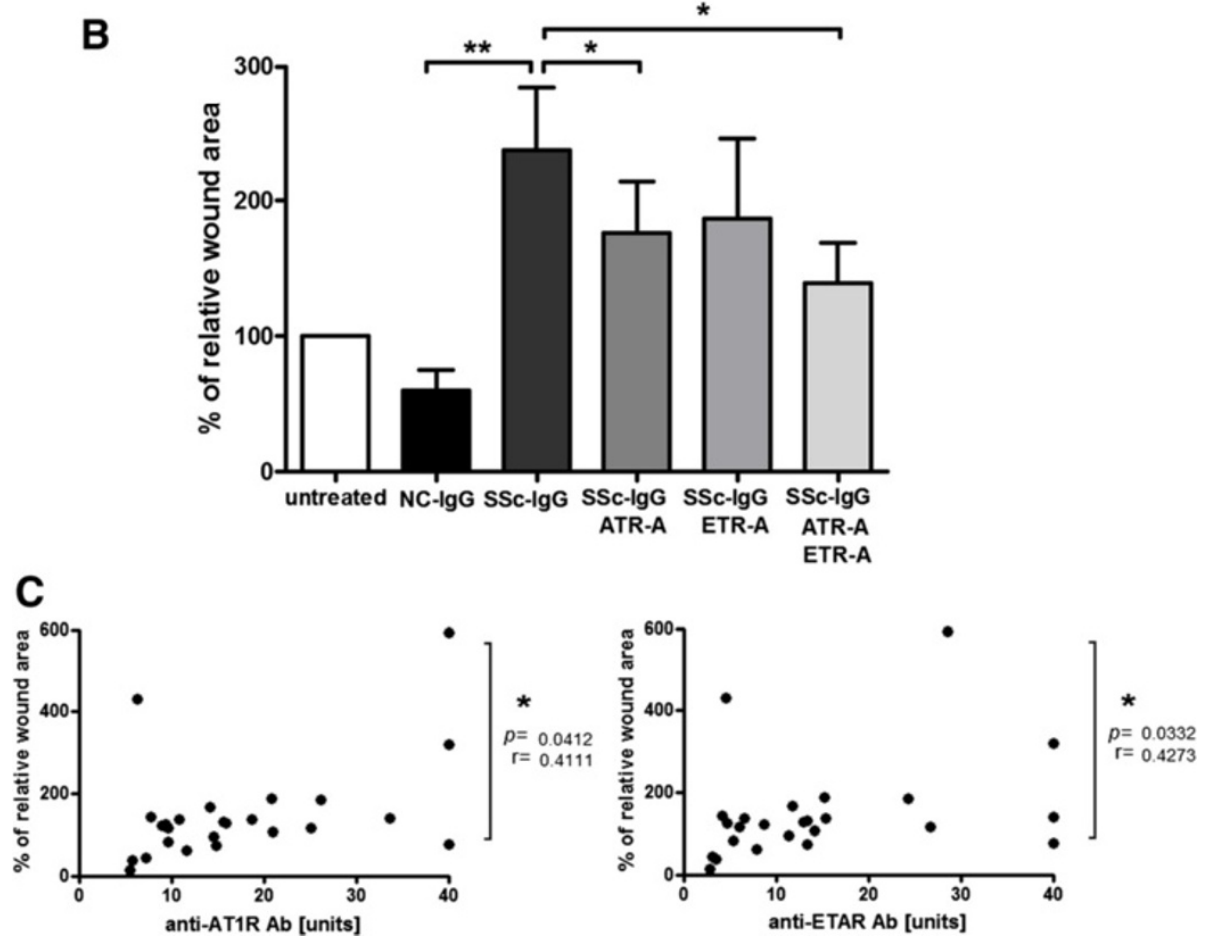

Figure 3 Diminished endothelial repair by treatment with anti-AT $\mathbf{R}_{1}$ and anti-ET ${ }_{A} R$ Ab-positive SSc-lgG. HMEC-1 treated with anti-AT $R$ and anti-ETA $R$ Ab-positive SSC-lgG reduce wound areas measured by a scratch assay. (A) Representative pictures of NC-lgG and of SSC-lgG-treated cells and indicated inhibitors. (B) After 24 hours, wound areas are significantly greater in SSc-lgG versus NC-lgG treatment (NC-lgG, $n=6,5 S c-l g G$ $n=6, P<0.01)$ and are significantly reduced by antagonists, as indicated $(P<0.05)$. Bar indicates 250 micron. Independent experiments were performed at least twice. Mean and SEM, ${ }^{* *} P<0.01$ and ${ }^{*} P<0.05$. (C) Wound area, as measurement of endothelial repair, shows a correlation to levels of anti-AT1R Abs and anti-ETAR Abs (NC-IgG, $n=11$; SSC-lgG, $n=14$; total $n=25)$. Spearman correlation.

reflected by endothelial dysfunction, expression of IL-8, and increased neutrophil migration into target tissues.

Involvement of both the angiotensin and the endothelin systems in SSc pathogenesis has been demonstrated previously: Elevated serum levels of Ang II and ET-1 in SSc patients were reported, as well as increased ET-1 levels in SSc lung fibrotic tissue, indicating their central role in SSc pathogenesis $[15,25,26]$. Also, a link between angiotensin and endothelin-receptor activation and fibrosis, perhaps the most prominent feature of SSc, was also suggested in the literature [26-28]. Activation of $A T_{1} R$ by anti-AT $R$ Abs was reported previously for 

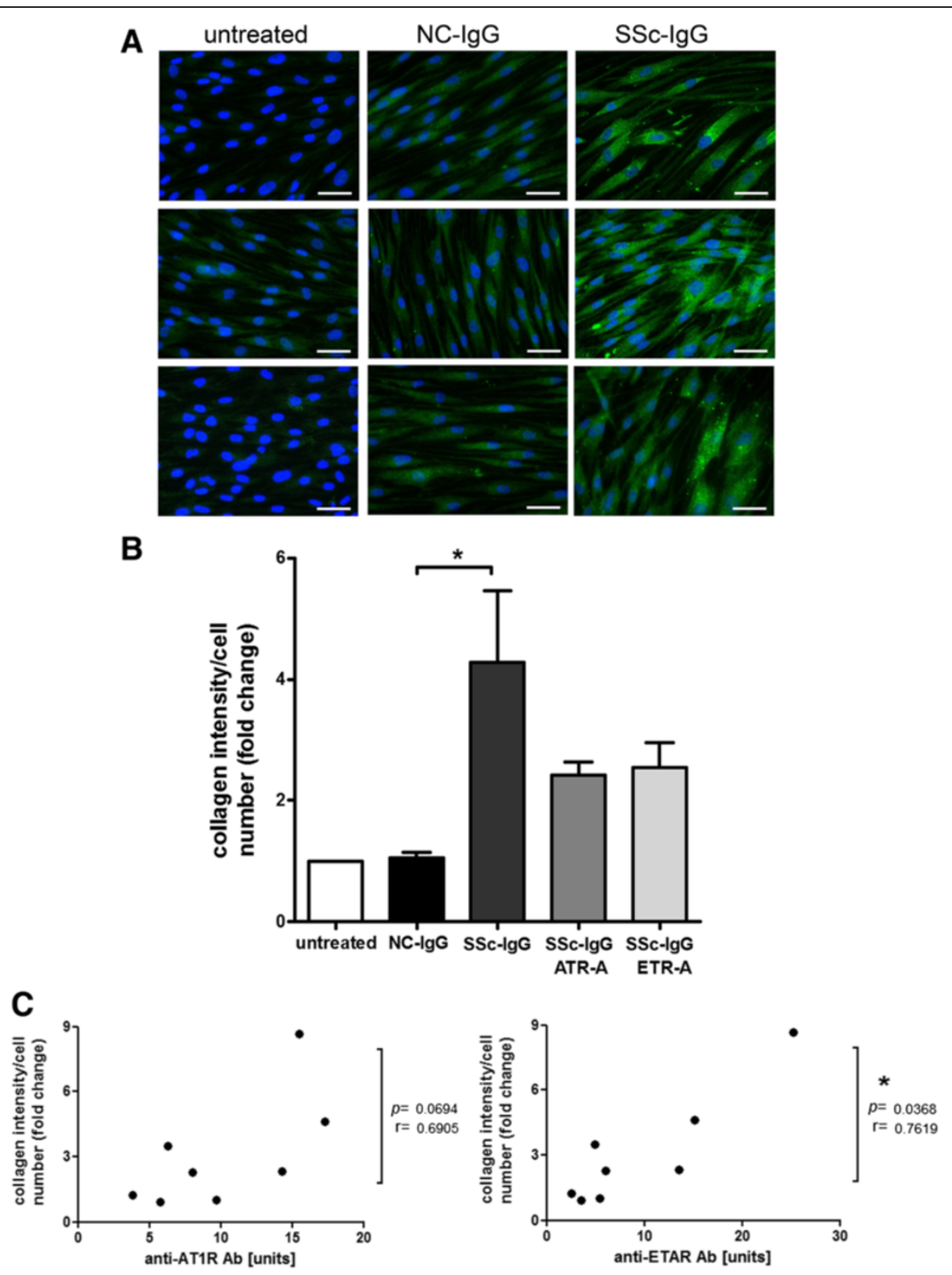

Figure 4 Induction of collagen expression in fibroblasts by anti-AT $R$ and anti-ET ${ }_{A} R$ Ab-positive SSc-lgG. Skin fibroblasts of healthy donors increase expression of type I collagen with anti-AT ${ }_{1} R$ and anti-ET $A$ A Ab positive SSC-lgG. (A) Expression of type I collagen analyzed with immunocytochemistry. Collagen expression is shown in green, and nucleic acid DAPI stain, in blue. Bar indicates $50 \mu$ m; shown are representative pictures. (B) Significant increase in type I collagen with SSc-lgG versus NC-lgG (NC-IgG $n=4$ and SSc-lgG $n=5, P<0.05$ ). Relative fluorescence intensity was analyzed and normalized to cell number for each sample. Mean and SEM, ${ }^{*} P<0.05$. (C) Collagen expression (type I collagen) shows a significant correlation to anti-ETAR Ab levels and a trend to anti-AT1R Ab levels (NC-IgG, $n=3$; SSc-lgG, $n=5$; total $n=8$; $P<0.05$ ).

Spearman correlation.

preeclampsia and renal-allograft rejection [24,29]. Overexpression of extracellular matrix components (ECM), of which collagen represents an important element, is a key aspect in fibrosis development $[12,14]$. Angiotensin- and endothelin-mediated collagen expression was demonstrated [17,27]. Accordingly, we found increased expression of collagen in healthy donor dermal fibroblasts after exposure to anti- $\mathrm{AT}_{1} \mathrm{R}$ and anti-ET $\mathrm{A} \mathrm{Ab}$-positive SScIgG. The intensity of collagen expression was significantly dependent on levels of anti-ET $\mathrm{T}_{\mathrm{A}} \mathrm{R}$ Abs, showing an Ab-dependent effect.

Besides the importance of fibrosis in SSc, many studies propose that microvascular damage and inflammation can precede fibrosis $[4,30]$. Additionally, autoimmune- 
A

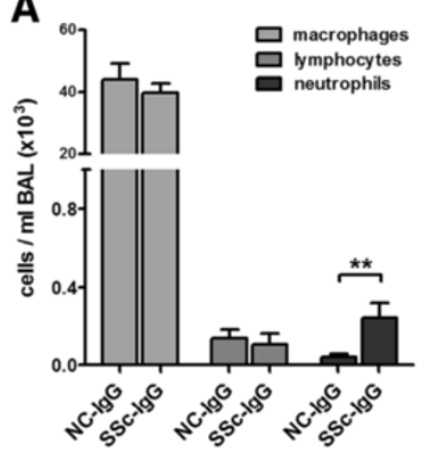

D

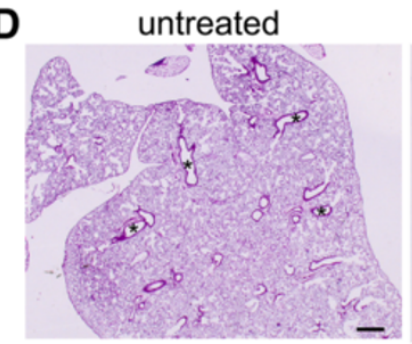

B

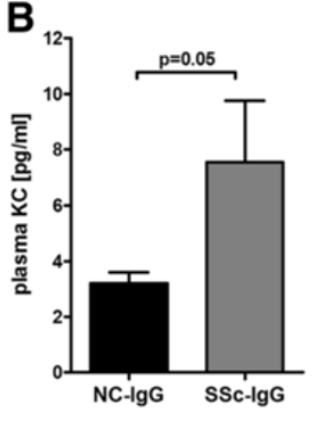

C

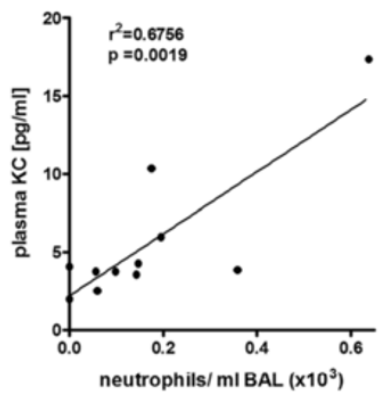

NC-IgG
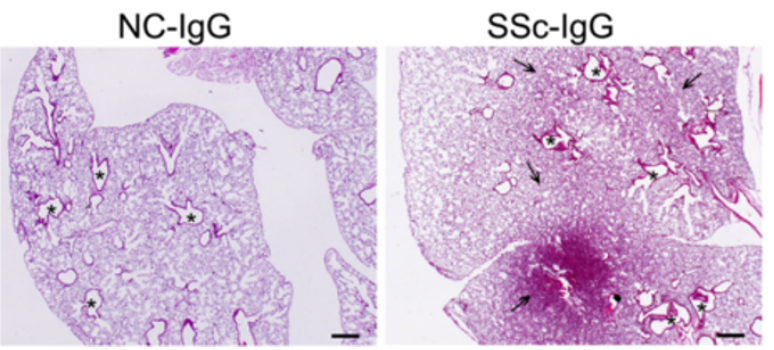

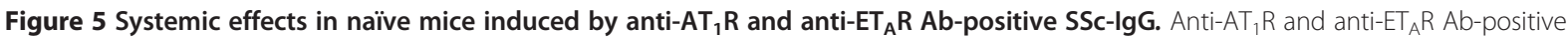
SSc-lgG transfer increases neutrophil recruitment and KC levels (murine IL-8 analogue) in mice. (A) Significantly increased neutrophil counts detected in BALF of mice treated with SSc-lgG compared with NC-IgG $(n=7 ; \mathrm{P}<0.01)$. (B) KC plasma levels in SSC-lgG-treated mice as compared with NC-lgG-treated mice are increased by trend (NC-lgG, $n=5 ;$ SSC-lgG, $n=6 ; P=0.05)$. (C) KC plasma levels significantly correlate with neutrophil counts in BALF (NC-IgG $n=5$, SSC-IgG, $n=6, r^{2}=0.6756, P=0.0019$, linear regression correlation). Mean and SEM, ${ }^{* *} P<0.01$. (D) Repeated treatment with $\lg$ G results in marked alterations of the lung structure of SSC-lgG-treated mice compared with NC-lgG or untreated mice. Shown are representative light-microscopy pictures, H\&E staining, $\times 12.5$ magnification; bar indicates $500 \mu m$. Asterisks indicate examples of airway vessels; arrows indicate elevated cell density in interstitial tissue.

mediated damage to endothelial cells has been demonstrated to cause endothelial dysfunction [31], which can lead to vessel leaks and lymphocyte infiltration [4,32]. In this regard, anti- $\mathrm{AT}_{1} \mathrm{R}$ and anti-ET $\mathrm{A}$ R Abs induced microvascular endothelial cell (HMEC-1) dysfunction after exposure to positive SSc-IgG, resulting in reduced endothelial repair in an Ab-level-dependent manner. Moreover, endothelial dysfunction was further reflected by VCAM-1 expression on endothelial cells. Recently, the concept of vascular leak was proposed to be a central feature of SSc pathogenesis, highlighting the importance of changes in the microvasculature in disease progression [33]. Our findings indicate a general disturbance of endothelial functions by SSc-IgG in vitro, which could probably also occur in vivo. However, this hypothesis must be tested in more detail in future experiments.

Furthermore, expression of the chemokine IL-8 with proinflammatory and profibrotic properties has been reported to be increased in sera, BALF, and fibroblasts in SSc $[7,8,10]$. Accordingly, we found increased mRNA and protein levels of IL-8 in HMEC-1 cells after exposure to anti- $\mathrm{AT}_{1} \mathrm{R}$ and anti-ET $\mathrm{A}$ Ab positive SSc-IgG. In line with this, the murine IL-8 functional homolog $\mathrm{KC}$ was found to be increased in plasma of naïve mice treated with SSc-IgG. Given the chemotactic abilities of IL-8, we congruously found increased neutrophil transendothelial migration toward supernatants of SSc-IgG-activated endothelial cells, which was dependent on IL-8. Increased neutrophil counts were also detected in vivo in BALF of naïve mice treated with SSc-IgG, where neutrophil counts correlated with $\mathrm{KC}$ plasma levels. In addition to signs of an inflammatory fibrosis, repeated passive transfer of anti$\mathrm{AT}_{1} \mathrm{R}$ and anti-ET $\mathrm{A}$ Ab-positive SSc-IgG resulted in marked structural alterations of lungs with increased cellular density in interstitial tissue. Our data suggest, furthermore, that these Abs can also activate angiotensin and endothelin receptors across both species because of high receptor homology [34,35].

Our study has some limitations, of which the most prominent is the use of total purified IgG instead of specifically purified anti- $\mathrm{AT}_{1} \mathrm{R}$ and anti-ET $\mathrm{A}$ A Abs. Instead, we here used receptor antagonists to demonstrate receptormediated activation, as previously reported $[21,29]$. Therefore, measured effects could partly result from other Abs, suggested by incomplete effect inhibition by receptor antagonists. Also, we cannot exclude the participation of other Abs present in IgG on the measured effects. However, we have focused on effects that have already been associated with angiotensin and endothelin-receptor activation. Another shortcoming is that the observed effects 
showed sometimes very high variability within tested samples, indicating the very complex nature of these Abs.

\section{Conclusions}

In summary, our in vitro results indicate an induction of proinflammatory and profibrotic events by anti- $\mathrm{AT}_{1} \mathrm{R}$ and anti-ET $\mathrm{T}_{\mathrm{A}} \mathrm{R}$ Ab-positive SSc-IgG that might also be present in vivo.

Our experimental data complement the association of anti-AT $\mathrm{A}_{1} \mathrm{R}$ and anti-ET $\mathrm{A} \mathrm{R}$ to clinical features of SSc, especially with interstitial lung disease. On the basis of these findings, we conclude that anti- $\mathrm{AT}_{1} \mathrm{R}$ and anti$\mathrm{ET}_{\mathrm{A}} \mathrm{R}$ Abs can activate angiotensin and endothelin receptor-expressing cells, among them some of the key players of SSc pathogenesis, and thus affect mechanisms of inflammation and fibrosis. Therefore, anti- $\mathrm{AT}_{1} \mathrm{R}$ and anti-ET $\mathrm{A}_{\mathrm{A}} \mathrm{R}$ Abs may present a novel future target in $\mathrm{SSc}$ therapeutic intervention.

\section{Abbreviations}

Ab: Autoantibody; Abs: autoantibodies; $A T_{1} R$ : angiotensin II type 1 receptor; ATR-A: angiotensin-receptor antagonism; BALF: bronchoalveolar lavage fluid; ECM: extracellular matrix; $\mathrm{ET}_{\mathrm{A}} \mathrm{R}$ : endothelin-1 type $\mathrm{A}$ receptor;

ETR-A: endothelin receptor antagonism; HMEC-1: human microvascular endothelial cell; IL-8: interleukin-8; NC-lgG: IgG from healthy donors; ROS: reactive oxygen species; SSc: systemic sclerosis; SSc-lgG: Anti-AT ${ }_{1}$, and anti-ET $T_{A} R, A b$-positive lgG of SSC patients.

\section{Competing interests}

Study was supported by an unrestricted grant from Actelion Pharmaceuticals Germany $\mathrm{GmbH}$; no other competing interests are involved.

\section{Authors' contributions}

AK, CT, MOB, JG, MR, DD, and GR participated in study design and data interpretation. AK participated in in vitro experiments. AK, CT, and RU participated in animal experiments. AK and CT performed statistical analyses. $\mathrm{HH}$ provided measurements of anti-AT ${ }_{1} \mathrm{R}$ and anti-ET $\mathrm{A}_{\mathrm{A}} \mathrm{A}$ Ab. MWo provided healthy donor-skin samples. MWi provided equipment for BALF analysis. AKü performed histologic preparation of lungs. G-RB, DD, and GR participated in study coordination. AK participated in manuscript preparation with support of all other authors, who read and approved of the manuscript.

\section{Acknowledgements \\ Study was supported by University Hospital Charité, Deutsche Stiftung Sklerodermie (DSS), Deutsche Forschungsgemeinschaft (SFB-TR84 C3 \& C6), ARTICULUM Fellowship, CellTrend GmbH, and Actelion Pharmaceuticals Germany GmbH. HMEC-1 were provided by H. D. Orzechowski (Shire GmbH, Berlin, Germany). Valsartan was a gift of D. N. Müller (Max Delbrück Center for Molecular Medicine, Berlin, Germany). Sitaxentan was provided by Pfizer Deutschland GmbH (Germany), and bosentan, by Actelion Pharmaceuticals Germany $\mathrm{GmbH}$}

\section{Author details \\ ${ }^{1}$ German Rheumatism Research Centre (DRFZ), A Leibniz Institute, Berlin, Germany. ${ }^{2}$ Department of Rheumatology and Clinical Immunology, University Hospital Charité, Luisenstraße 13, Berlin 10117, Germany. ${ }^{3}$ Department of Infectious Diseases and Pulmonary Medicine, University Hospital Charité, Berlin, Germany. ${ }^{4}$ Department of Inner Medicine, University Hospital Charité, Berlin, Germany. ${ }^{5}$ Department of Rheumatology and Clinical Immunology, University Hospital Split, Split, Croatia. ${ }^{6} \mathrm{C}$ ellTrend GmbH, Luckenwalde, Germany. ${ }^{7}$ Department of Dermatology, University Hospital Charité, Berlin, Germany. ${ }^{8}$ Department of Nephrology and Intensive Care Medicine, University Hospital Charité, Berlin, Germany.}

Received: 30 May 2013 Accepted: 3 January 2014

Published: 28 January 2014

\section{References}

1. LeRoy EC, Black C, Fleischmajer R, Jablonska S, Krieg T, Medsger TA Jr, Rowell N, Wollheim F: Scleroderma (systemic sclerosis): classification, subsets and pathogenesis. J Rheumatol 1988, 15:202-205.

2. Varga J, Abraham D: Systemic sclerosis: a prototypic multisystem fibrotic disorder. J Clin Invest 2007, 117:557-567.

3. Riemekasten G, Philippe A, Nather M, Slowinski T, Muller DN, Heidecke $H$, Matucci-Cerinic M, Czirjak L, Lukitsch I, Becker M, Kill A, van Laar JM, Catar R, Luft FC, Burmester GR, Hegner B, Dragun D: Involvement of functional autoantibodies against vascular receptors in systemic sclerosis. Ann Rheum Dis 2011, 70:530-536.

4. Fleischmajer R, Perlish JS: Capillary alterations in scleroderma. J Am Acad Dermatol 1980, 2:161-170.

5. Prescott RJ, Freemont AJ, Jones CJ, Hoyland J, Fielding P: Sequential dermal microvascular and perivascular changes in the development of scleroderma. J Pathol 1992, 166:255-263.

6. Kahaleh MB, Sherer GK, LeRoy EC: Endothelial injury in scleroderma. J Exp Med 1979, 149:1326-1335.

7. Schmidt K, Martinez-Gamboa L, Meier S, Witt C, Meisel C, Hanitsch LG, Becker MO, Huscher D, Burmester GR, Riemekasten G: Bronchoalveolar lavage fluid cytokines and chemokines as markers and predictors for the outcome of interstitial lung disease in systemic sclerosis patients. Arthritis Res Ther 2009, 11:R111.

8. Kadono T, Kikuchi K, Ihn H, Takehara K, Tamaki K: Increased production of interleukin 6 and interleukin 8 in scleroderma fibroblasts. J Rheumatol 1998, 25:296-301.

9. Furuse S, Fujii H, Kaburagi Y, Fujimoto M, Hasegawa M, Takehara K, Sato S: Serum concentrations of the CXC chemokines interleukin 8 and growth-regulated oncogene-alpha are elevated in patients with systemic sclerosis. J Rheumatol 2003, 30:1524-1528.

10. Codullo V, Baldwin HM, Singh MD, Fraser AR, Wilson C, Gilmour A, Hueber AJ, Bonino C, McInnes IB, Montecucco C, Graham GJ: An investigation of the inflammatory cytokine and chemokine network in systemic sclerosis. Ann Rheum Dis 2011, 70:1115-1121.

11. Crestani B, Seta N, Palazzo E, Rolland C, Venembre P, Dehoux M, Boutten A, Soler P, Dombret MC, Kahn MF: Interleukin-8 and neutrophils in systemic sclerosis with lung involvement. Am J Respir Crit Care Med 1994, 150:1363-1367.

12. LeRoy EC: Increased collagen synthesis by scleroderma skin fibroblasts in vitro: a possible defect in the regulation or activation of the scleroderma fibroblast. J Clin Invest 1974, 54:880-889.

13. Jimenez SA, Feldman G, Bashey RI, Bienkowski R, Rosenbloom J: Co-ordinate increase in the expression of type I and type III collagen genes in progressive systemic sclerosis fibroblasts. Biochem J 1986, 237:837-843.

14. Bocchieri MH, Christner PJ, Henriksen PD, Jimenez SA: Immunological characterization of (tight skin/NZB)F1 hybrid mice with connective tissue and autoimmune features resembling human systemic sclerosis. J Autoimmun 1993, 6:337-351.

15. Kawaguchi Y, Takagi K, Hara M, Fukasawa C, Sugiura T, Nishimagi E, Harigai M, Kamatani N: Angiotensin II in the lesional skin of systemic sclerosis patients contributes to tissue fibrosis via angiotensin II type 1 receptors. Arthritis Rheum 2004, 50:216-226.

16. Shi-Wen X, Chen Y, Denton CP, Eastwood M, Renzoni EA, Bou-Gharios G, Pearson JD, Dashwood M, du Bois RM, Black CM, Leask A, Abraham DJ: Endothelin-1 promotes myofibroblast induction through the ETA receptor via a rac/phosphoinositide 3-kinase/Akt-dependent pathway and is essential for the enhanced contractile phenotype of fibrotic fibroblasts. Mol Biol Cell 2004, 15:2707-2719.

17. Kawaguchi Y, Suzuki K, Hara M, Hidaka T, Ishizuka T, Kawagoe M, Nakamura $\mathrm{H}$ : Increased endothelin-1 production in fibroblasts derived from patients with systemic sclerosis. Ann Rheum Dis 1994, 53:506-510.

18. van den Hoogen F, Khanna D, Fransen J, Johnson SR, Baron M, Tyndall A, Matucci-Cerinic M, Naden RP, Medsger TA Jr, Carreira PE, Riemekasten G, Clements PJ, Denton CP, Distler O, Allanore Y, Furst DE, Gabrielli A, Mayes MD, van Laar JM, Seibold JR, Czirjak L, Steen VD, Inanc M, Kowal-Bielecka O, Müller-Ladner U, Valentini G, Veale DJ, Vonk MC, Walker UA, Chung L, et al: 2013 classification criteria for systemic sclerosis: an american college of rheumatology/european league against rheumatism collaborative initiative. Arthritis Rheum 2013, 65:2737-2747.

19. Heit B, Liu L, Colarusso P, Puri KD, Kubes P: PI3K accelerates, but is not required for, neutrophil chemotaxis to fMLP. J Cell Sci 2008, 121:205-214. 
20. Sironi L, Calvio AM, Arnaboldi L, Corsini A, Parolari A, de Gasparo M, Tremoli E, Mussoni L: Effect of valsartan on angiotensin Il-induced plasminogen activator inhibitor-1 biosynthesis in arterial smooth muscle cells. Hypertension 2001, 37:961-966.

21. Dechend R, Viedt C, Muller DN, Ugele B, Brandes RP, Wallukat G, Park JK, Janke J, Barta P, Theuer J, Fiebeler A, Homuth V, Dietz R, Haller H, Kreuzer Luft FC: AT1 receptor agonistic antibodies from preeclamptic patients stimulate NADPH oxidase. Circulation 2003, 107:1632-1639.

22. Maurer B, Busch N, Jungel A, Pileckyte M, Gay RE, Michel BA, Schett G, Gay S, Distler J, Distler O: Transcription factor fos-related antigen-2 induces progressive peripheral vasculopathy in mice closely resembling human systemic sclerosis. Circulation 2009, 120:2367-2376.

23. http://frodo.wi.mit.edu/primer3/.

24. Zhou CC, Zhang Y, Irani RA, Zhang H, Mi T, Popek EJ, Hicks MJ, Ramin SM, Kellems RE, Xia Y: Angiotensin receptor agonistic autoantibodies induce pre-eclampsia in pregnant mice. Nat Med 2008, 14:855-862.

25. Coral-Alvarado P, Quintana G, Garces MF, Cepeda LA, Caminos JE, Rondon F, Iglesias-Gamarra A, Restrepo JF: Potential biomarkers for detecting pulmonary arterial hypertension in patients with systemic sclerosis. Rheumatol Int 2009, 29:1017-1024.

26. Abraham DJ, Vancheeswaran R, Dashwood MR, Rajkumar VS, Pantelides $P$, Xu SW, du Bois RM, Black CM: Increased levels of endothelin-1 and differential endothelin type $A$ and $B$ receptor expression in sclerodermaassociated fibrotic lung disease. Am J Pathol 1997, 151:831-841.

27. Stawski L, Han R, Bujor AM, Trojanowska M: Angiotensin II induces skin fibrosis: a novel mouse model of dermal fibrosis. Arthritis Res Ther 2012, 14:R194.

28. Denton CP, Black CM, Abraham DJ: Mechanisms and consequences of fibrosis in systemic sclerosis. Nat Clin Pract Rheumatol 2006, 2:134-144.

29. Dragun D, Muller DN, Brasen JH, Fritsche L, Nieminen-Kelha M, Dechend R, Kintscher U, Rudolph B, Hoebeke J, Eckert D, Mazak I, Plehm R, Schönemann C, Unger T, Budde K, Neumayer HH, Luft FC, Wallukat G: Angiotensin II type 1-receptor activating antibodies in renal-allograft rejection. $N$ Engl I Med 2005, 352:558-569.

30. Nguyen VA, Sgonc R, Dietrich H, Wick G: Endothelial injury in internal organs of University of California at Davis line 200 (UCD 200) chickens, an animal model for systemic sclerosis (scleroderma). J Autoimmun 2000, 14:143-149.

31. Sgonc R, Gruschwitz MS, Boeck G, Sepp N, Gruber J, Wick G: Endothelial cell apoptosis in systemic sclerosis is induced by antibody-dependent cell-mediated cytotoxicity via CD95. Arthritis Rheum 2000, 43:2550-2562.

32. Katsumoto TR, Whitfield ML, Connolly MK: The pathogenesis of systemic sclerosis. Annu Rev Pathol 2011, 6:509-537.

33. Frech TM, Revelo MP, Drakos SG, Murtaugh MA, Markewitz BA, Sawitzke AD, Li DY: Vascular leak is a central feature in the pathogenesis of systemic sclerosis. J Rheumatol 2012, 39:1385-1391.

34. Richard V, Solans V, Favre J, Henry JP, Lallemand F, Thuillez C, Marie I: Role of endogenous endothelin in endothelial dysfunction in murine model of systemic sclerosis: tight skin mice 1. Fund Clin Pharmacol 2008, 22:649-655

35. Inaba S, Iwai M, Furuno M, Kanno H, Senba I, Okayama H, Mogi M, Higaki J Horiuchi M: Temporary treatment with AT1 receptor blocker, valsartan, from early stage of hypertension prevented vascular remodeling. Am J Hypertens 2011, 24:550-556.

\section{Submit your next manuscript to BioMed Central and take full advantage of:}

- Convenient online submission

- Thorough peer review

- No space constraints or color figure charges

- Immediate publication on acceptance

- Inclusion in PubMed, CAS, Scopus and Google Scholar

- Research which is freely available for redistribution

Submit your manuscript at www.biomedcentral.com/submit
C Biomed Central 